\title{
Left ventricular output during postnatal circulatory adaptation in healthy infants born at full term
}

\author{
P WINBERG, M JANSSON, L MARIONS, AND B P W LUNDELL \\ Department of Paediatrics, Karolinska Institute, Sachs' Children's Hospital, Stockholm, Sweden
}

SUMMARY Left ventricular output was measured non-invasively at predefined time intervals from $<15$ minutes to 72 hours after birth in 16 infants who had been born at full term. The blood flow velocity in the ascending aorta was measured by a range gated Doppler technique and multiplied by the cross sectional diameter measured by cross sectional and $\mathbf{M}$ mode echocardiography. Left ventricular output remained high in the first two hours, $235-243 \mathrm{ml} / \mathrm{min} / \mathrm{kg}$, despite a $10 \%$ decrease in heart rate. The fall in heart rate was compensated for by a $15 \%$ increase in stroke volume. Between 2 and 24 hours there was a significant fall in mean (SD) left ventricular output to $187(35) \mathrm{ml} / \mathrm{min} / \mathrm{kg}$ caused mainly by a reduction in stroke volume. The fall in left ventricle output after two hours may reflect an adaptation to the decreased demand on the left ventricle as the ductus constricts.

Postnatal circulatory transition entails fundamental changes in the systemic and pulmonary circulations. ${ }^{1}$ During fetal life the two ventricles work in parallel, the left ventricle mainly supplying the upper body with blood, particularly the myocardium and the brain. After birth and completed circulatory transition, the left ventricular output provides all systemic perfusion. This leads to an increased volume demand on the left ventricle. ${ }^{1}$ The physiological left to right shunt through the open ductus arteriosus soon after birth may also contribute to an increased volume load on the left ventricle.

The ability to increase output by increased stroke volume is thought to be limited in the fetus and newborn because of lower myocardial compliance ${ }^{2}$ and contractile reserve ${ }^{3}$ compared with the adult. Despite this, left ventricular output in the lamb is more than doubled after birth. $^{4}$ Because noninvasive methods of investigation have been developed relatively recently, most of our knowledge about the haemodynamic changes after birth is based on studies in animals. With ultrasound imaging and Doppler techniques left ventricular output can now be studied non-invasively in newborn infants as well. Several non-invasive studies have been carried out in the postnatal period but in no study has left ventricular output been measured directly after birth. ${ }^{5-7}$

The aim of this investigation was to study the postnatal changes in the left ventricular output of newborn infants by frequent measurements at pre- 8 cise time intervals starting almost immediately after birth.

\section{Subjects and methods}

Sixteen healthy infants born at full term, each with a normal neonatal course, were studied. Infants born by elective caesarean sections were chosen so that the first recording could be made within 15 minutes of the birth. Indications for caesarean section were: cephalopelvic disproportion, breech presentation, and previous caesarean section. Maternal epidural anaesthesia (bupivacaine) was used in 13 cases, and general anaesthesia (barbiturates, halothane, and nitrous oxide) in three cases.

Blood samples were taken at birth from the umbilical arteries of the double clamped cord for measurement of $\mathrm{pH}$ and packed cell volume. A combined range gated and continuous multifrequency Doppler velocimeter (ALFRED, Vingmed A/S) was used to measure blood flow velocities in the ascending aorta. A high pass filter was set at 400 $\mathrm{Hz}$ to reduce noise from vessel wall motions. With the infant supine under a radiant warmer, the $5 \mathrm{MHz}$ transducer with a tip $8 \mathrm{~mm}$ in diameter was positioned in the suprasternal notch. Guided by the audio signal, the transducer was directed towards the ascending aorta. The echoes from the aortic valves were identified and the sample volume, with 
a length of $4 \mathrm{~mm}$, was placed 5-10 $\mathrm{mm}$ above the valves. Care was taken to find the most high pitched frequencies by small changes in the probe angle. The space average velocity (the average over the cross section of the aorta) (fig 1) and the temporal mean of the space average velocity signals were recorded on an oscillograph (Mingograph 34, Siemens Elema). A stable recording over 20-30 heart beats with the highest Doppler shift was selected, and the corresponding mean flow velocity was determined.

Cross sectional and $\mathbf{M}$ mode echocardiography were performed immediately after each Doppler recording using a $7.5 \mathrm{MHz}$ sector scanner and an echocardiograph (Technicare). The end systolic internal diameter (trailing edge to leading edge) of the ascending aorta, 5-10 $\mathrm{mm}$ above the valves, was measured on a hard copy of the parasternal long axis $M$ mode recording, and a mean taken over 8-10 consecutive heart beats (fig 2). The calculated cross sectional area was multiplied by the mean flow

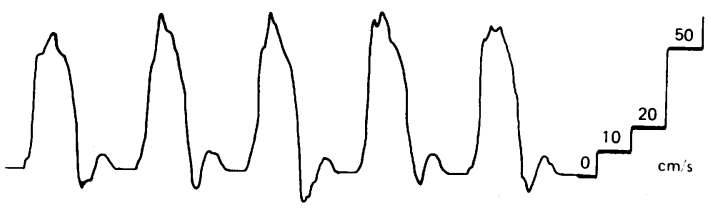

Fig 1 Average cross sectional flow velocity recording from ascending aorta.

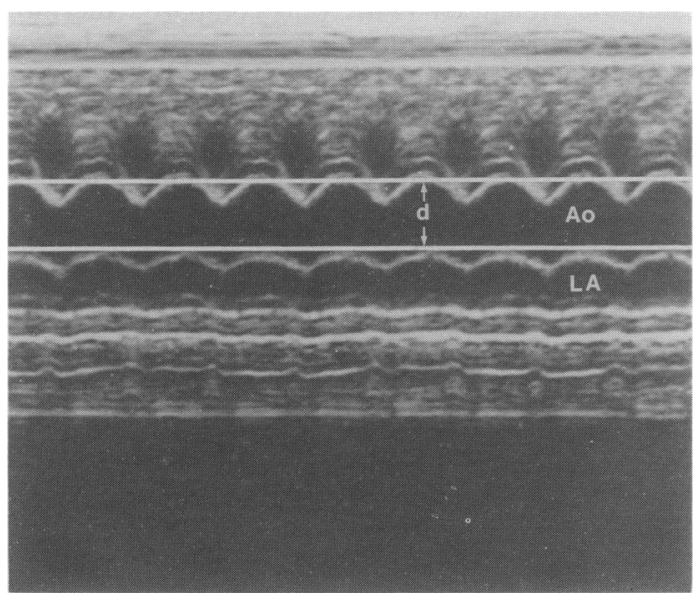

Fig 2 Long axis $M$ mode recording from ascending aorta (Ao), and left atrium (LA). Measurement of internal aortic diameter $(d)$ in end systole. velocity, and divided by the body weight to give left ventricular output in $\mathrm{ml} / \mathrm{min} / \mathrm{kg}$. Stroke volume was calculated by dividing left ventricular output by heart rate. Blood pressure was measured noninvasively in connection with each Doppler recording using the oscillometric technique (Omega 1400, In Vivo Research Laboratories). The width of the cuff on the right upper arm was carefully chosen to minimise errors. ${ }^{8}$

All recordings on the same infant were made by the same investigator, and were performed at $<15$ minutes, 30 minutes, 2 hours, 5 hours (4-6), 24 hours (22-26), and 72 hours (70-74) after birth. The two last recordings were performed about 30 minutes after feeding. The sleep stage was clinically assessed as quiet sleep or rapid eye movement sleep. Informed consent was obtained from the parents before delivery, and the study was approved by the local committee of ethics. The statistical evaluation was made by multifactorial analysis of variance, using a model where individual subjects, postnatal age, and sleep stage were sources of variation. Tukey's hourly significant difference test was used for multiple comparisons of means. ${ }^{9}$

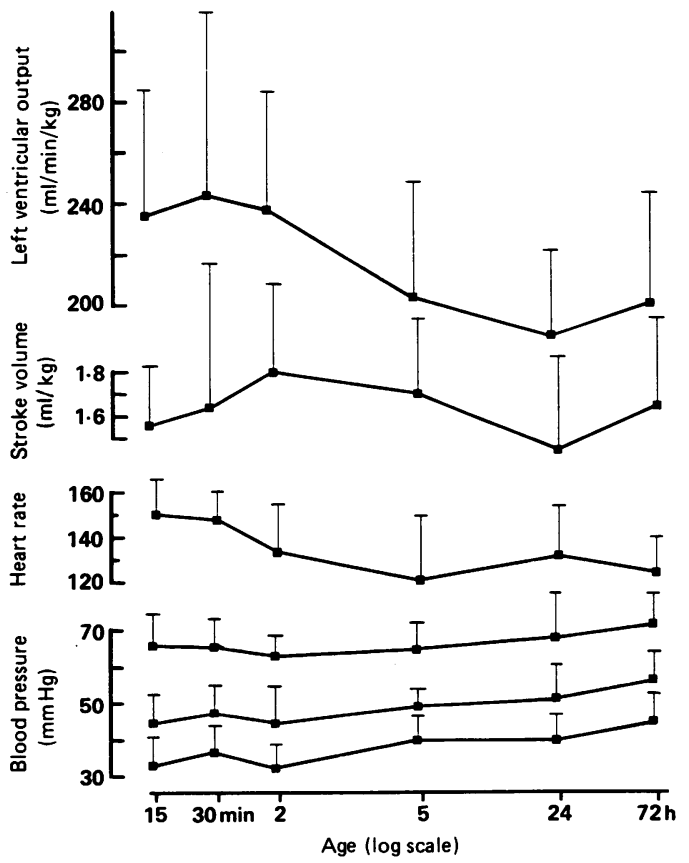

Fig 3 Mean (SD) left ventricular output, stroke volume, heart rate, and arterial blood pressure during postnatal circulatory adaptation in 16 healthy infants born at full term. 


\section{Results}

Each infant was healthy and had a normal neonatal course. Mean (SD) gestational age was $38.5(0.7)$ weeks and birth weight was 3370 (344) g. Umbilical arterial blood $\mathrm{pH}$ and packed cell volume were 7.32 $(0.04)$, and $0.46(0.05)$, respectively. Recordings were obtained on all occasions in all infants. The Doppler measurements were made at a sampling depth of $3.3(0.3) \mathrm{cm}$.

Mean left ventricular output, stroke volume, heart rate, and arterial blood pressure are shown in fig 3. Heart rate decreased with increasing age and was significantly lower at 2 hours than at birth $(p<0 \cdot 01)$. Blood pressure did not change significantly before 2 hours. Between 2 and 72 hours systolic, diastolic, and mean pressure rose significantly $(\mathrm{p}<0 \cdot 01)$. Pulse pressure decreased from 31 $(4.8)$ to $25(6.9) \mathrm{mm} \mathrm{Hg}$ between 2 and 5 hours $(\mathrm{p}<0.01)$. The mean diameter of the ascending aorta was $9.8(1.0) \mathrm{mm}$. No significant differences in aortic diameter were obtained between measurements. The variation coefficients for the aortic diameter measurements varied among the infants from 2 to $13 \%$ (mean $6 \%$ ).

Left ventricular output remained high for the first two hours, decreased at five hours in 13 of the 16 infants $(p<0 \cdot 01)$, and then decreased further until 24 hours in 11/16 infants $(p<0 \cdot 01)$. Left ventricular output was lower $(p<0 \cdot 01)$ when the infants were sleeping but did not differ between quiet and rapid eye movement sleep. Left ventricular stroke volume increased from the first measurement to a maximum at 2 hours $(p<0.01)$, and then decreased until 24 hours $(\mathrm{p}<0 \cdot 01)$.

\section{Discussion}

In this study left ventricular output was determined at several predefined time intervals after birth. The recording intervals were chosen so that the main circulatory changes during the normal transition should be included. Using strictly non-invasive techniques, minimal stress was inflicted on the infants and the transition itself should accordingly not have been disturbed. Only infants born by caesarean section were included. The lower plasma catecholamine concentrations found in infants born this way ${ }^{10}$ and the drugs used for maternal anaesthesia might influence both myocardial contractility ${ }^{11}$ and left ventricular output. ${ }^{12}$ The smaller placental transfusion during caesarean section could also affect the cardiovascular state. ${ }^{13}$ Differences in left ventricular output have also been reported. Gessner et al showed somewhat higher left ventricular output in vaginally delivered infants compared with those delivered by caesarean section, but they found no difference in ductus shunting during the first few hours after birth. ${ }^{14}$

A close correlation has been found between invasive methods and the Doppler technique for measurement of cardiac output in newborn and older infants, although the Doppler does not include coronary blood flow. ${ }^{51516}$ We calculated left ventricular output from the mean flow velocity and the inner diameter of the ascending aorta. Others have used the leading edge method (from the external surface of the anterior aortic wall to the internal surface of the posterior wall) ${ }^{6}{ }^{15}$ as proposed by the American Society of Echocardiography in $1978,{ }^{17}$ as these structures may be easier to define and should permit more precise measurements in adults. The leading edge method overestimates the diameter, and the left ventricular output, however, by including one vessel wall thickness. With the higher ultrasound frequencies used in neonates, and with modern ultrasound equipment, the trailing to leading edge method may be more appropriate. In spite of this, the mean diameter in our group was almost the same as that given by Walther $e t$ al in a similar group of infants, using the leading edge method. ${ }^{18}$ The variations in aortig diameter between measurements probably reflece errors in method rather than true changes in dia meter because there were no systematic changes over the observation period in our study. Accordingly, the mean diameter of each child was used for calculation of the left ventricular output. Goldberg et al did not overestimate left ventricular output with the leading edge method, ${ }^{5}$ compared with dye dilution measurements, which is in contrast to the results of Mellander et al, who compared thermodilution with different ultrasound methods for measurement of left ventricular output. ${ }^{16}$ Mellander et al reported that the leading edge method overestimated left ventricular output by $30 \%$, compared with $2 \%$ for the inner diameter technique, and gave a somewhat higher variation. As the velocity profile in the ascending aorta is not flat, ${ }^{19}{ }^{20}$ using the maximum flow velocity gives an overestimation of flow whereas the mean flow velocity produces more correct results. ${ }^{21}$ Although the maximum velocity recording is less dependent on complete insonation of the vessel, using it in neonates and older infants gives only a slightly smaller variation, while it produces a large overestimation of left ventricular output. ${ }^{16}$ Hence the product of cross sectional mean flow velocity and the cross sectional area derived from the inner diameter should yield the best measure of the output.

The decrease in heart rate between the first measurement and 2 hours may reflect hormonal and 
metabolic changes-for example, the end of the catecholamine surge at birth. ${ }^{22}$ Despite this, left ventricular output remained high. A possible explanation for the sustained high left ventricular output at 2 hours is that it is a consequence of a left to right shunt through the open ductus, which other studies have suggested occurs at this time. ${ }^{142324}$ This explanation is supported by the decrease in diastolic blood pressure, and increase in stroke volume up to 2 hours. From 2 to 5 hours and then to 24 hours, left ventricular output, stroke volume, and pulse pressure decreased. This favours the concept of a diminishing shunt starting before 5 hours of age. This seems to occur earlier than expected, but previous studies with invasive techniques may have interfered with the normal circulatory transition and delayed ductus constriction. ${ }^{23}{ }^{24}$ Echocardiographic signs of ductus constriction have also been shown recently at 4 hours in $80 \%$ of healthy infants born at full term. ${ }^{25}$ Even though ductal shunting can be detected non-invasively with the Doppler technique 24 hours after birth in over half of the healthy infants born at full term, ${ }^{26}$ this only gives a qualitative measure of the shunt and the time period when it is haemodynamically important may be much shorter and occur earlier. At present there is no available non-invasive technique for accurate quantitation of the ductus flow, but studies of left ventricular systolic time intervals also seem to show early disappearance of a haemodynamically important ductus shunt. ${ }^{27}$

The sleep/wake state may also influence left ventricular output. At the first two recordings the infants were awake and left ventricular output was high, whereas at the two last recordings most infants were asleep and left ventricular output was lower. Multifactorial analysis of variance, however, showed that postnatal age had a significant influence on left ventricular output independent of sleep/wake state.

The increase in stroke volume compensated for the fall in heart rate between 30 minutes and 2 hours, and left ventricular output was unchanged. Between 2 and 24 hours the stroke volume decreased, heart rate remained nearly constant, and left ventricular output declined. Thus left ventricular output seems to depend more on stroke volume than on heart rate during this period.

In this study left ventricular output was 237 $\mathrm{ml} / \mathrm{min} / \mathrm{kg}$ at 2 hours and $200 \mathrm{ml} / \mathrm{min} / \mathrm{kg}$ after 24 hours. These values are of the same magnitude as has previously been reported in invasive studies. Gessner et al found left ventricular output to be 233 $\mathrm{ml} / \mathrm{min} / \mathrm{kg}$ between 30 minutes and 2 hours of age in infants born by caesarean section, ${ }^{14}$ and Emmanouilides et al reported $209 \mathrm{ml} / \mathrm{min} / \mathrm{kg}$ in newborn infants without shunts. ${ }^{28}$ Previous Doppler studies have shown somewhat higher left ventricular output, ${ }^{56}$ probably explained by differences in signal processing and measurements of the aortic diameter. If the systemic perfusion (ductus flow excluded) was maintained at $200 \mathrm{ml} / \mathrm{min} / \mathrm{kg}$, the measured left ventricular output suggests a $15-20 \%$ left to right shunt at 2 hours. If the shunt was larger, however, it would mean reduced systemic flow at this age. Whether the systemic perfusion is maintained or compromised by the ductus shunt cannot be determined from our data. The cerebral blood flow, however, does not seem to be reduced when assessed in a similar group of infants at the same time intervals. ${ }^{29}$

We conclude that left ventricular output remains high during early postnatal transition in spite of decreasing heart rate. A fall in left ventricular output occurs after 2 hours of age, possibly as a result of decreased demand on the left ventricle as the ductus constricts.

This study was supported by Expressen Prenatal Research Foundation, Stiftelsen Samariten, the General Maternity Hospital Foundation, the Swedish Society for Medicine, and Sällskapet Barnavård.

\section{References}

${ }^{1}$ Rudolph AM. Changes in the circulation after birth. Congenital heart diseases. Chicago: Year Bood Medical Publishers, 1974: 17-28.

${ }^{2}$ Friedman WF. The intrinsic physiologic properties of the developing heart. Prog Cardiovasc Dis 1972;15:87-111.

3 Friedman WF, Kirkpatrick SE. In situ physiological study of the developing heart. Recent Advances in the Study of Cardiac Structure and Metabolism 1975;5:497-504.

${ }^{4}$ Klopfenstein HS, Rudolph AM. Postnatal changes in the circulation, and responses to volume loading in sheep. Circ Res 1978;42:839-45.

5 Alverson DC, Eldridge MW, Dillon T, Yabek SM, Berman W. Noninvasive pulsed Doppler determination of cardiac output in neonates and children. $J$ Pediatr 1982;101:46-50.

6 Walther FJ, Siassi B, Ramadan NA, Ananda A, Wu PYK. Pulsed Doppler determinations of cardiac output in neonates: normal standards for clinical use. Pediatrics 1985;76:829-33.

${ }^{7}$ Hirsimäki H, Kero P, Wanne O, Erkola R, Mako Z. Doppler derived cardiac output in healthy newborn infants in relation to physiological patency of the ductus arteriosus. Pediatr Cardiol 1988;9:79-83.

${ }^{8}$ Sonesson S-E, Broberger U. Arterial blood pressure in the very low birth weight neonate. Acta Paediatr Scand 1987;76:338-41.

9 Daniel W. Biostatistics: a foundation for analysis in the health sciences. 3rd ed. New York: John Wiley, 1983:224-6.

${ }^{10}$ Irestedt L, Lagercrantz H, Hjelmdahl P, Hägnevik K, Belfrage $P$. Fetal and maternal plasma catecholamine levels at elective cesarean section under general or epidural anesthesia versus vaginal delivery. Am J Obstet Gynecol 1982;142:1004-10.

11 Block A, Covino BG. The effect of local anesthetic agents on cardiac conduction and contractility. Reg Anaesth 1981;6:55-61.

12 Liu P, Feldman HS, Covino BM, Giasi BR, Covino BG. Acute cardiovascular toxicity of intravenous amide local anesthetic in anesthetized ventilated dogs. Anesth Analg 1982;61:317-22.

13 Yao AC, Lind J. Placental transfusion. Springfield: Charles C Thomas, 1982:103-7. 
${ }^{14}$ Gessner I, Krovetz LJ, Bensin RW, Prystowsky H, Stenger V, Eitzman DV. Hemodynamic adaption in the newborn infant. Pediatrics 1965;36:752-62.

15 Goldberg S, Sahn D, Allen H, Valdes-Cruz L, Hoenecke H, Carnahan Y. Evaluation of pulmonary and systemic blood flow by 2-dimensional Doppler echocardiography using fast Fourier transform spectral analysis. Am J Cardiol 1982;50:1394-400:

${ }^{16}$ Mellander M, Sabel K-G, Caidahl K, Solymar L, Eriksson B. Doppler determination of cardiac output in infants and children: comparison with simultaneous thermodilution. Pediatr Cardiol 1987;8:241-6.

17 Sahn DJ, DeMaria A, Kissolo J, Weyman A. Recommendations regarding quantitation in M-mode echocardiography: results of a survey of echocardiographic measurements. Circulation 1978; 58:1072-83.

18 Walther FJ, Siassi B, King J, Wu PYK. Normal values of aortic root measurement in neonates. Pediatr Cardiol 1985;6:61-4.

${ }^{19}$ Clark C, Schultz DL. Velocity distribution in aortic flow. Cardiovasc Res 1973;7:601-13.

${ }^{20}$ Levy b, Targett RC, Bardou A, Mcllroy MB. Quantitative ascending aortic Doppler blood velocity in normal human subjects. Cardiovasc Res 1985;19:383-93.

${ }^{21}$ Lundell BPW, Lindstrom DP, Arnold TG. Neonatal cerebral blood flow velocity. An in vitro validation of the pulsed Doppler technique. Acta Paediatr Scand 1984;73:810-5.

22 Lagercrantz H, Bistoletti P, Nylund L. Sympathoadrenal activity in the fetus during delivery and at birth. In: Stern L, Salle B, Friis-Hansen B, eds. Intensive care in the newborn. New York: Masson, 1981:1-12.
23 Adams FH, Lind J. Physiologic studies on the cardiovascular status of normal newborn infants (with special reference to the ductus arteriosus). Pediatrics 1957;19:431-7.

${ }^{24}$ Moss AJ, Emmanouilides G, Duffie ER Jr. Closure of the ductus arteriosus in the newborn infant. Pediatrics 1963;30: 25-30.

${ }^{25}$ Hiraishi S, Misawa H, Oguchi K, et al. Two-dimensional Doppler echocardiographic assessment of closure of the ductus arteriosus in normal newborn infants. $J$ Pediatr 1987;111: 755-60.

${ }^{26}$ Gentile R, Stevenson G, Dooley T, Kawabori I, Pearlman A. Pulsed Doppler echocardiographic determination of time of ductal closure in normal newborn infants. $J$ Pediatr 1981;98: 443-8.

${ }^{27}$ Lundell BPW, Wallgren CG. Assessment of left ventricular adaptation to extrauterine circulation. Systolic time intervals in the newborn infant. Acta Paediatr Scand 1982;71:745-52.

${ }^{28}$ Emmanouilides GC, Moss AJ, Monset-Couchard M, Marcano BA, Rzeznic B. Cardiac output in newborn infants. Biol Neonate 1970;15:186-97.

${ }^{29}$ Sonesson S-E, Winberg P, Lundell BPW. Early postnatal changes in intracranial arterial blood flow velocities in term infants. Pediatr Res 1987;22:461-4.

Correspondence to Dr P Winberg, Sachs' Children's Hospital, S-116 69 Stockholm, Sweden.

Accepted 30 May 1989 